\title{
Educating tomorrow's registered nurse: views of the Council of Deans of Health
}

\author{
Emeritus Professor Alan Glasper, from the University of Southampton, discusses the Council of Deans of Health's \\ recent discussion paper giving their initial views on the key outcomes of future preregistration nurse education
}

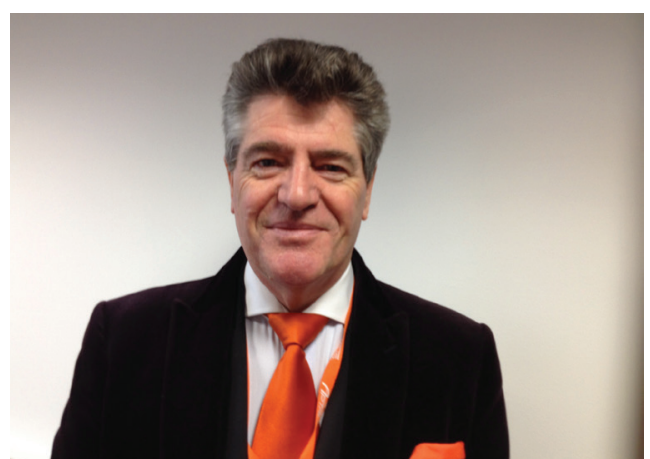

$\mathcal{1}$ n August 2016, the Council of Deans of Health $(\mathrm{CoDH})$ published their initial views on the key outcomes of future registered nurse education, across all four fields of practice. This discussion paper, Educating the Future Nurse (CoDH, 2016), was precipitated by the Raising the Bar: Shape of Caring review published in March 2015 by Health Education England (HEE). Widely known as the Willis report, its aim was to ensure that throughout their careers, nurses and care assistants receive consistently excellent education and training to support high-quality care delivery for the foreseeable future (HEE, 2015).

One of the key recommendations of the Willis report was that nurses follow a more generic preparation programme of study. He believes that future student nurses should undergo a 2-year whole-person core education programme, followed by a 1 -year chosen specialist programme and a subsequent preceptorship year after registration. However, some members of the smaller fields of practice such as children's nurses have concerns that a 2-year core education programme might become too generic and focused on physical adult health care (Glasper, 2016). Generic nurse preparation does not equate to the registered general nurse programme of yesteryear, which, although it gave taster placements in areas such as paediatrics and mental health, was on the whole orientated towards the care of adults. Indeed, as far back as 1944, Sir Alan Moncrieff, then a well-known paediatrician, gave a paper at the Royal College of Nursing entitled Upon the Future of the Nursing of Sick Children. His key message to his audience then (as now) was that children's nursing is not a specialty, but general care at a special age period (Glasper and Charles-Edwards, 2002).

Moncrieff's message still resonates todaythat each of the fields of practice has generic elements that will need to be reflected in any core programme and honed through the proposed post-registration preceptorship year. Hence, nurses from all the fields of practice must acquire detailed knowledge pertinent to their discipline to meet the specific physiological, psychological, emotional and social needs of their patients in all healthcare settings. New standards of nurse education should allow tomorrow's nurses to understand the complexities of their client group's needs.

\section{Council of Deans discussion paper}

The CoDH represents the UK's university faculties who teach nurses, midwives and allied health professionals. With regard to nursing and midwifery alone the members of the council educate more than half of the entire health professional workforce in the UK. Clearly, it is vital that these various institutes of higher education have a strong influence on the future direction of nursing and midwifery, although it is important to stress too that they do not set the standards for courses leading to registration - a role that currently belongs to the Nursing and Midwifery Council (NMC).

Educating the Future Nurse is intended to stimulate debate on the future of preregistration nursing education - a debate that has already started with the appointment of Professor Dame Jill Macleod Clark as lead advisor on the development of new NMC preregistration nursing education standards. In this context, it is important to stress that the current preregistration standards for nurse education were published in 2010 after a long period of consultation and debate.
However, following the Willis review, the NMC has recognised that these standards, comprising 152 pages of detailed competencies and subclauses, are too complex and too focused on processes rather than outcomes. So, in January 2016, the NMC approved plans to undertake a review of the competencies for new nurses entering the profession. Dame Jill will undoubtedly factor the Council of Dean's discussion paper into her own deliberations on behalf of the NMC as she and her colleagues begin to determine the new preregistration standards of nurse education over the coming months (CoDH, 2016). The NMC will formally consult on the standards between April and June 2017, and it is envisaged that the final set of standards will be published by early 2018 . The NMC believes that all approved education institutions will develop the new programmes for implementation in the academic year 2019/20.

As the debate gathers momentum, the $\mathrm{CoDH}$ discussion paper gives their initial views on the key outcomes of the future configuration of undergraduate nurse education. For reasons of space, I will focus only on its key elements in this article.

\section{The key elements}

The CoDH groups its suggested educational outcomes across the four themes of the NMC's Code (2015): prioritise people, practise effectively, preserve safety and promote professionalism and trust. As there have been many discussions about how much time a student nurse should spend in practice to develop all the skills and competencies required of a registered nurse, the $\mathrm{CoDH}$ paper gives this issue full consideration. However, the deans recognise that graduates of the new programmes will not enter practice until 2022 and that many of them will still be in practice for 40 years or more. With this in mind, they have decided to undertake some 'future gazing'. The deans have drawn on the myriad 
documents and polices that have endeavoured to predict future trends in health care- not only the growth in the number of people living with long-term conditions, but also diseases yet to emerge. Who, in the 1970s, could have foreseen the emergence of AIDS or the massive rise in type 2 diabetes that has accompanied the obesity epidemic of the new millennium?

What is known and recognised in the dean's paper is that the UK population is going to grow to 71 million by 2023, up by $9 \%$ since 2014 . This needs to be factored into the accompanying changes to the nursing workforce, which is getting older; by 2023 , the mean age of registered nurses will be 48 , with growing numbers opting for part-time work.

One of the key areas identified by the deans, which they believe will affect nurse education, is the multi-professional context and specific contribution of the profession to the overall 'envelope' of care delivery. Clearly, Dame Jill, one of the architects of shared learning among students of the health sciences, will want to see this aspect of training fully embedded in any new standards (O'Halloran et al, 2006).

The deans have articulated one important aspect as to the future blueprint for nurse education - that of a competency-based education versus disruptive innovation. This concept describes the ramifications when something fundamental happens in an industry (in this case health care) that changes the whole paradigm, as in the emergence of a new disease, technology or treatment (Agency for Healthcare Research and Quality, 2016).

The deans have also presented another conundrum for nurse educators: should they teach nurses a range of technical skills or teach nurses the skills to learn? This is sometimes at odds with employers, who naturally want nurses to arrive at the point of registration with a large toolkit of skills, whereas the deans recognise that, as tomorrow's nurses will be working more autonomously in a range of clinical settings, they should be equipped with transferable skills to enable them to adapt and grow their competencies as the need arises.

\section{Deans' vision based on the four themes of the NMC Code}

\section{ت Prioritise people}

The deans believe that future registered nurses will need to be highly effective communicators who can enable self-care by supporting people to make informed choices and manage their own care in all settings. Nurses must promote health and wellbeing, as they will continue to be pivotal in helping reduce health inequalities through health promotion and supporting people achieve optimal health and wellbeing at every life stage. The future registered nurse will need to be educated to function effectively as a key coordinator of care delivery, as people's needs and services continue to change, with greater integration of health and social care.

\section{Practice effectively}

The deans are confident that tomorrow's nurses must develop flexibility to care for the whole person, whatever the setting, and that these nurses will need a comprehensive understanding of mental health, of the needs of people with learning disabilities, and of physical health across the lifespan, whether working with adults or children. Effective practice must be underpinned by nurses who have a good grasp of information technology, as the seeds of telehealth and telecare have already been sown and will change the whole structure of healthcare delivery. Such structural changes demand a curriculum to help nurses function as lifelong learners, equipped with the skills to mentor and teach others. Tomorrow's nurse will also have to be equipped to respond to new and emerging diseases and, where necessary, work in other parts of the world.

\section{Preserve safety}

Future nurses must be taught how to delegate safely and effectively. This is because today's healthcare profile will change, and nurses will have to manage a wide range of healthcare environments where care will be delegated to other team members. Additionally, tomorrow's nurses will have to acquire higher levels of more complex skills to meet expectations that they will be able to diagnose and assess patients' needs. This will call for nurses with knowledge drawn from evidence-based practice, which will help them prevent errors in care delivery and support quality improvement.

\section{Promote professionalism and trust}

Tomorrow's nurse must retain patient trust and confidence in the profession, and those nurses will be required to take an increasingly strong leadership role. A good grasp of research will be essential in helping tomorrow's nurses develop the confidence to emerge from preregistration courses as critical thinkers who are equipped with the knowledge to deliver care based on best evidence, underpinned by a thirst for innovation and entrepreneurialism.

\section{KEY POINTS}

- In August 2016, the Council of Deans of Health published a discussion paper to stimulate debate on the future of preregistration nursing education

- Professor Dame Jill Macleod Clark has been appointed as lead advisor on the development of new preregistration nursing education standards

- Nurses from the smaller fields of practice are concerned that the proposed 2-year core programme might become too adult-health orientated

- Tomorrow's nurses will need a comprehensive understanding of mental health, learning disabilities and physical health across the human life span, whether working with adults or children

\section{Conclusion}

This CoDH discussion paper is very comprehensive and will clearly help the NMC develop the new standards for preregistration nurse education. The paper does not attempt to challenge the current configuration of the nursing profession with its four discrete fields of practice, which will hearten many nurse educators who might have feared that new standards might be orientated towards the reintroduction of yesterday's general nurse. However, in discussing the connection between preregistration and postregistration education, the deans do recognise its significance in the ongoing debate on whether to retain the four fields of nursing in the future. BJN

Agency for Healthcare Research and Quality (2016) Advancing Excellence in Health Care. https:// innovations.ahrq.gov (accessed 22 September 2016) Council of Deans of Health (2016) Educating the Future Nurse - a paper for discussion. http://tinyurl.com/ z $4 \mathrm{kbvbc}$ (accessed 22 September 2016)

Glasper A, Charles-Edwards I (2002) The child first and always: the registered children's nurse over 150 years. Part two. Paediatr Nurs 14(5): 38-43

Glasper A (2016) Ensuring the integrity of children's nursing education. Br J Nurs 25(6): 342-3

Health Education England (2015) Raising the Bar: Shape of Caring. HEE/NMC, London

Nursing and Midwifery Council (2015) The Code: Professional standards of practice and behaviour for nurses and midwives. NMC, London

O'Halloran C, Hean S, Humphris D, Macleod-Clark (2006) Developing common learning: the new generation project undergraduate curriculum model.J Interprof Care 20(1): $12-28$ 